Conclusions Historical wood dust exposure levels in Ontario were high, with a large proportion of measurements above the exposure limits. These data indicate that hardwood dust levels have been as high in Canada as they were in Europe in some industries and occupations. The development of this JEM for Canadian exposure to wood dust is a key step in determining whether differences from the European situation exist via a new epidemiologic study.

\title{
Poster-discussion: Exposure assessment \\ HISTORICAL EXPOSURE TO WOOD DUST IN ONTARIO, \\ CANADA
}

Cheryl Peters, ${ }^{1}$ Paul Demers, ${ }^{2}$ Victoria Arrandale ${ }^{3}{ }^{1}$ University of British Columbia, Vancouver, Canada; ${ }^{2}$ Cancer Care Ontario, Toronto, Canada; ${ }^{3}$ University of Toronto, Toronto, Canada

10.1136/oemed-2011-100382.251

Objectives Sinonasal cancer due to wood dust exposure is well-recognised as an occupational cancer in Europe, but not in North America, possibly due to differences in tree species or exposure levels. As the first step in developing an exposure matrix for an epidemiologic study, we characterised occupational exposure to wood dust in Ontario.

Methods Exposure data was obtained from Ontario (collected for surveillance and compliance purposes). Industry and occupation codes were recorded for linkage with population data. Simple descriptive analyses of wood dust exposure by industry and occupation were prepared.

Results There were 3734 wood dust samples available (1780 hardwood, 1430 softwood, 524 not classified). Interestingly, $73 \%$ were above the current threshold limit value of $1.0 \mathrm{mg} /$ $\mathrm{m}^{3}$ and $26 \%$ were above the historical TLV of $5 \mathrm{mg} / \mathrm{m}^{3}$. After removing outliers, the mean concentration of hardwood dust samples was $5.6 \mathrm{mg} / \mathrm{m}^{3}$ (GM: $\left.2.4 \mathrm{mg} / \mathrm{m}^{3}\right)$ and for softwoods was $3.9 \mathrm{mg} / \mathrm{m}^{3}$ (GM: $\left.1.8 \mathrm{mg} / \mathrm{m}^{3}\right)$. A slight downward trend in mean concentration over time was observed. Most samples (2975) were taken in the wood products and furniture manufacturing industries. 